\title{
Emergency surgical workload in a teaching hospital
}

\author{
P. Bhattarai \\ Correspondence to: Dr. Pallav Bhattarai, Nepalgunj Medical College, Kohalpur, Nepal \\ Email: antislim53@hotmail.com
}

\begin{abstract}
Introduction: Emergency operations are life saving and it may account for over $50 \%$ of surgical admissions depending upon the place. Its impact on the skill development in a teaching hospital is very important. However the impact on service provision and implications for training are difficult to quantify. We analyzed ten months data of emergency operations done at Kohalpur Teaching Hospital.

Methods: Data on emergency surgical operations over twelve months was collected including patient demographics, diagnosis, and operation and analyzed according to the operation performed and age-groups.

Results: There were 535 emergency surgical operations over ten months; $20.7 \%$ were under 14 years of age, $48.7 \%$ were between 15 -39 years of age and $30.4 \%$ patients were more than 39 years age. The commonest operations performed were from gastrointestinal cases (38.6\%), orthopedic (21.4\%), and wounds (20.5\%).

Conclusions: Children constituted one fourth of the total operations indicating peripheral hospital should have provision of a paediatric surgical team to have the optimum service. Resource planning should be based on more comprehensive, prospective data such as these.
\end{abstract}

Keywords: Emergency, surgical operations, teaching hospital.

\section{Introduction}

Emergency admissions account for $46 \%$ to $57 \%$ of all surgical admissions. ${ }^{1-3}$ The operations performed depend upon the availability of resources and manpower. In developing countries, most of the skilled manpower are unevenly distributed. Majority of this skilled manpower are confined to major cities.

There are no contemporaneous studies concerning the nature and volume of emergency surgical operations in Nepal. The impact of the emergency surgical workload on surgical practice is not only determined by overall volume but also by patient demographics, appropriateness of referral, centralization, diagnoses, and required surgical operations. ${ }^{4}$ This study sought to identify the current patterns related to emergency operations from a single peripheral hospital.

\section{Methods}

All emergency rooms (ER) surgical admissions over ten months (2064 Shrawan to 2065 Baisakh) were recorded retrospectively. Information was obtained from computer entered data of the hospital. The diagnosis was determined as mentioned in the post-operative notes which were entered in the computer.

\section{Results}

535 emergency surgeries were recorded of which 261(48.7\%) were in the age group of $15-39$ years, $163(30.4 \%)$ were more than 40 years and $111(20.7 \%)$ were birth up to 14 years (Fig 1).

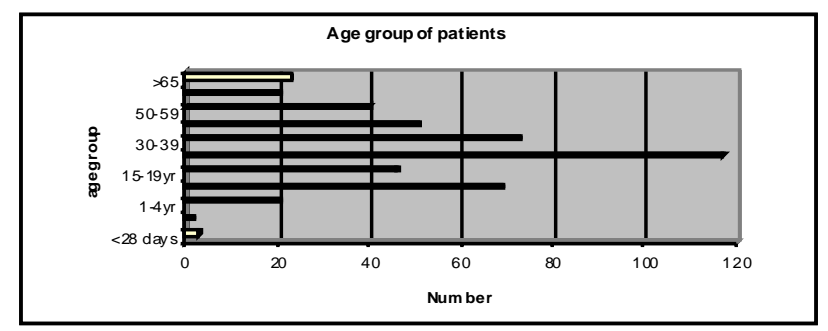

Fig. 1: Age group of patients 
In all the age groups, the commonest system in which the operations were done was gastrointestinal system (38.6\%) followed by musculoskeletal system (21.4\%).

In paediatric patients, the commonest system that was involved was gastrointestinal (43.03\%) followed by orthopaedic (36.7\%) and wounds (20.25\%) (Fig 2).

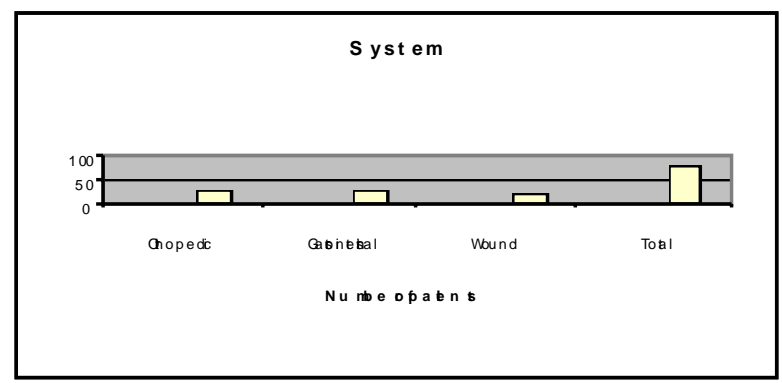

Fig. 2: Paediatric Cases

In females the lower segment caesarean section (LSCS) was done almost all cases. The LSCS was commonest in 20-29 years (67.1\%) (Fig 3).

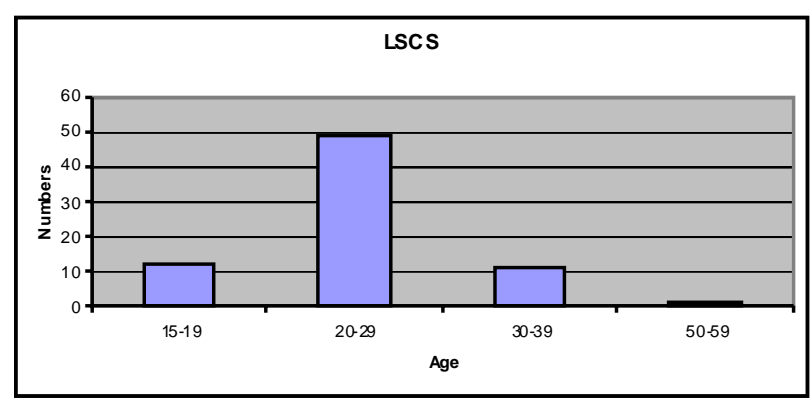

Fig.3: LSCS age group

Gastrointestinal operations were performed in 207 (38.6\%) of cases. Of this exploratory laparotomy was done in $63.76 \%$ of cases. Appendicectomy and cholecystectomy were perfomed in $15.4 \%$ and $5.7 \%$ of cases respectively. The laparotomy was performed maximum in 40-49 year age group (Fig 4).

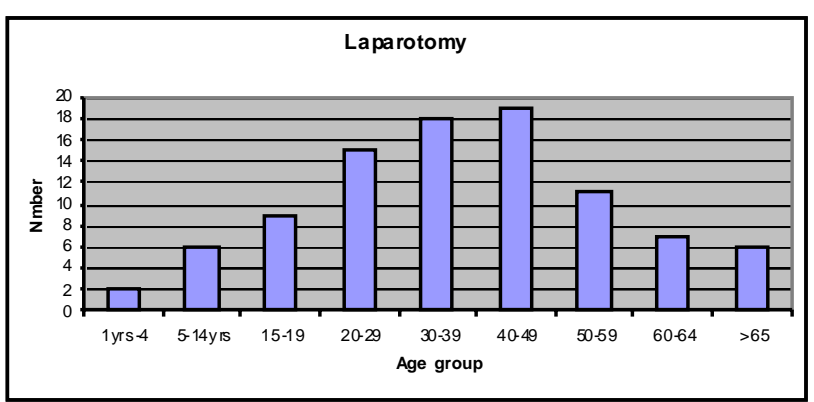

Fig. 4: Exploratory laparotomy
In 115 (21.4\%) cases, orthopedic operations were preformed. Closed reduction and open reduction with K-wire fixation were the commonest procedures performed i.e., 20.8\% and $13.9 \%$ respectively (Fig 5).

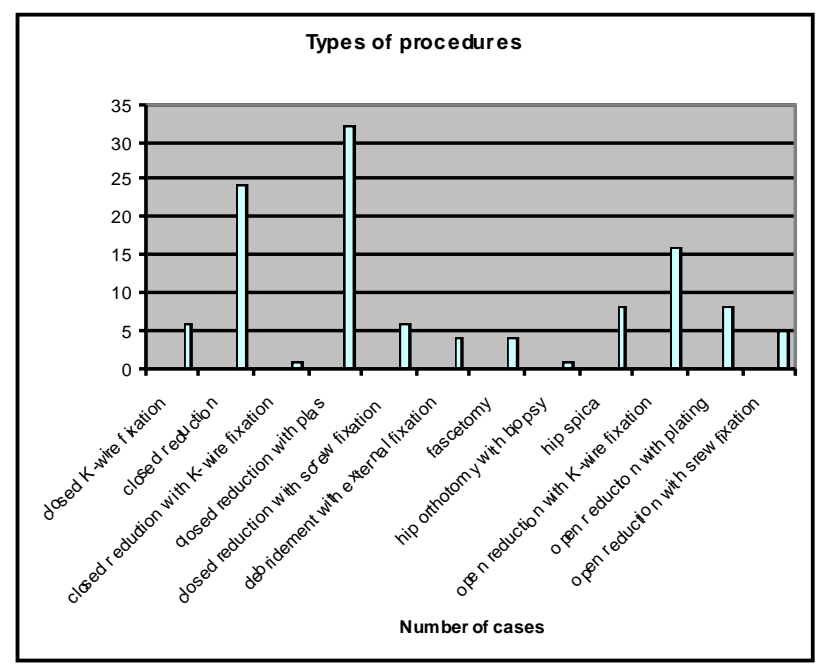

Fig. 5: Types of procedures

\section{Discussion}

This is the only medical college in the western region. As a result, there are higher admissions of trauma patients and emergency delivery care compared to the rest of hospitals in the western region.

The numbers of appendicectomies performed (15.4\%) were higher in comparison to the study done by Tuong A MaiPhan, et al (6.9\%). ${ }^{5}$ However, it is similar in comparison to other studies (15\% appendicectomy in Dawson study). ${ }^{3}$ The orthopaedic trauma cases as seen in Toung A Mai-Phan, et al (8.8\%) is much lower in comparison to this study (21.4\%). In our case, no head injury was seen in the register. This may reflect the fewer fast moving vehicles in this part of the country.

The exploratory laparotomy is high (63.7\%). The high laparotomy reflects the common abdominal emergencies that can survive for few days in high hills and can be brought to this centre.

This study shows that this hospital could be a major trauma centre and tertiary teaching hospital that will offer an array of training opportunities for the trainee surgeon through exposure to a wide-range of poly-trauma and emergency surgical patients requiring urgent surgical decisions and frequent operative intervention and a rapid turnover. 


\section{Conclusions}

These operations indicate that there are enough cases for the teaching of undergraduate and postgraduate students in Nepalgunj Medical College. Significant patients were less than 14 years old including neonates which emphasize the necessity of pediatric surgeons in a teaching hospital.

\section{References}

1. Capewell S. The continuing rise in emergency admissions. BMJ. 1996 Apr 20;312(7037):991-2.

2. Cobb RA, Baigrie RJ, Reece-Smith H, Faber RG. The workload of a surgical unit in a district general hospital. Ann R Coll Surg Engl. 1989;71(5):299-302.

3. Dawson EJ, Paterson-Brown S. Emergency general surgery and the implications for specialisation. Surgeon. 2004 Jun;2(3):165-70.

4. Allen-Mersh TG, Earlam RJ. General surgical workload in England and Wales. Br Med J (Clin Res Ed). 1983 Oct 15;287(6399):1115-8.

5. Mai-Phan TA, Patel B, Walsh M, Abraham AT, Kocher HM. Emergency room surgical workload in an inner city UK teaching hospital. World J Emerg Surg. 2008 May 30;3:19. 